\title{
In vivo biocompatibility assessment of (PTFE-PVDF-PP) terpolymer-based membrane with potential application for glaucoma treatment
}

\author{
Rafał Leszczynski • Ewa Stodolak · Jarosław Wieczorek • \\ Jolanta Orlowska-Heitzman • Teresa Gumula • \\ Stanislaw Blazewicz
}

Received: 11 February 2010/Accepted: 12 July 2010/Published online: 23 July 2010

(C) The Author(s) 2010. This article is published with open access at Springerlink.com

\begin{abstract}
The aim of the work was to evaluate the in vivo biological behaviour of polymeric membrane materials for glaucoma implants. The base material was biostable synthetic terpolymer (PTFE-PVDF-PP) with proved biocompability (PN-EN ISO 10993). The samples manufactured in the form a membrane were subjected to chemical and physical treatment to create an open pore system within the polymer matrix. As a porogenic phase biodegradable natrium alginate in a fibrous form was employed. The non-perforating deep sclerectomy technique was performed in a rabbit model. The clinical observations were made after 14 and 30 days. During the study clinical symptoms of a moderate degree were observed, and histopathological changes were typical for foreign body implantation. At the end stage of the study no significant difference in histopathological assessment was found between control and experimental group. Similarities observed in both groups and relatively mild histopathological changes in the tissue surrounding the implant indicate
\end{abstract}

R. Leszczynski

Department of Ophthalmology, Medical University of Silesia, Katowice, Poland

E. Stodolak $\cdot$ T. Gumula $\cdot$ S. Blazewicz $(\square)$ Department of Biomaterials, Faculty of Materials Science and Ceramics, University of Science and Technology, Al.

Mickiewicza 30, 30-059 Krakow, Poland

e-mail: blazew@agh.edu.pl

J. Wieczorek

Department of Biotechnology of Animal Reproduction, National

Research Institute of Animal Production, Balice, Poland

J. Orlowska-Heitzman

Department of Pathomorphology, Jagiellonian University, Krakow, Poland that the observed symptoms come from a deep scleral trauma caused by surgery, and not by the presence of the implant itself.

\section{Introduction}

According to WHO data, in 2002 about 37 million people are blind worldwide. Glaucoma is one of the leading causes of blindness (12.3\%, 4.4 million). At present 7 million people is blind because of glaucoma. It is assumed that in 2010 the number of blind people will increase to 8.4 million and in 2020 to over 11 million. At the same time, the number of patient suffering from glaucoma will increase to 60.5 million in 2010 and over 80 million in 2020 [1]. Standard procedures in glaucoma therapy are conservative (pharmacological) treatment, laser therapy and surgical treatment [2,3]. Surgery used as a therapy after other treatment strategies, such as medications and laser surgery, have failed to maintain intraocular pressure and to control course of disease. It is also indicated when the rapid eyeball injury with visual impairment and significant decrease of quality of life is observed [2,3]. The standard surgical procedures for glaucoma treatment, like trabeculectomy, iridectomy or deep sclerectomy are highly effective. They are connected, however with some complications, like intraocular infections, an excessive scar formation, perforation of anterior chamber, hypotony, choroidal detachment, maculopathy and cataract [2-5]. Moreover, none of these approaches has yet been shown to be successful clinically in the long term.

Due to introduction of nonpenetrating procedures a number of complications decreased and safety of patients operated for glaucoma improved. In order to prolong the efficacy of this treatment ocular drainage intrascleral 
implants are applied. Such implants improve the conditions of fluid transport in the operated eye. Such implants differ distinctly from currently used Seton implants in their shape and functioning. Two groups of implants are used in nonpenetrating treatment. The first group of implants undergo bioresorption (collagen, sodium hyaluronate-based implants) and the second one is made of biostable polymers. At present, however only one type of biostable implants made from Poly-Megma is clinically applied, namely T-flux (Laboratory La Rochelle, France) [6-9].

Implants made of organic materials like, collagen, hialuronate undergo biodegradation process within 6-9 months after surgery. This process may be accompanied by an unfavourable growth of connective tissue and as a consequence an increase of the intraocular pressure is observed. In the postoperative phase the pressure can be lowered by a laser procedure known as goniopuncture [9, 10]. Synthetic membrane materials based on expanded PTFE, PP or silicone polymers may cause a chronic inflammation. Moreover, their functional parameters, like elasticity, are often not sufficient for performing surgery $[11,12]$. The attempts are undertaken to produce an intrascleral implant made of a synthetic material, which would be well tolerated after implantation, convenient for operative procedure and would ensure long-lasting filtration of aqueous fluid on an appropriate level. Increasing demands for new and improved ophthalmic devices for glaucoma treatment cause the necessity to elaborate new biomaterials that could better withstand this highly specific biological environment.

The work presents the in vivo study of the polymer membranes designed for glaucoma treatment. The details of the membranes preparation, their physical and mechanical characteristics and in vitro assessment are described elsewhere [13-15]. Our preliminary study revealed that the elaborated membranes containing a stable interconnected open pore system are biocompatible and have hydrophobic surface inhibiting adsorption of aqueous humor proteins and blockage of membrane pores $[16,17]$. Such a stable porous microstructure may ensure a better permeability for aqueous humor constituents, whereas a hydrophobic nature of the membrane pores prevents adhesion of peptides and proteins present in an aqueous medium.

\section{Materials and methods}

\subsection{Implants}

The PTFE-PVDF-PP terpolymer (Aldrich Chemical Co., USA) and sodium alginate (Biopolymer, AS Protanal LF 20/60) were selected to prepare the samples in the form of porous membrane. Selected terpolymer is a biostable synthetic material with proved biocompability (PN-EN ISO 10993). Water soluble sodium alginate in the form of chopped (short) fibres of $200 \pm 25 \mu \mathrm{m}$ long was used as a porogenic component. Weighted amount of fibres was mixed with the polymer solution. Subsequently, the mixture was poured on a Petri dish and dried at ambient temperature for $48 \mathrm{~h}$ to evaporate the solvent and the samples in the form of thin foils were obtained. In order to remove the porogenic phases and to create open porosity within the polymeric material the foils were immersed in distilled water at $80^{\circ} \mathrm{C}$, for $80 \mathrm{~h}$. This procedure of the material preparation allowed to obtain the samples in the form of membrane having a high open porosity (45\%) and interconnected pore system. Porous membrane implants of equilateral triangle shape of $3 \mathrm{~mm}$ side length were cut from the foil.

\subsection{Methods: plan of experiment}

The non-perforating deep sclerectomy (NPDS) was performed in rabbits in both eyeballs. In one eyeball deep sclerectomy with intrascleral insertion of the implant was performed (study group). In the same animal, on the opposite side, only deep sclerectomy was performed, without implant insertion (control group). The eyeball was randomly selected to study and to control groups. The period of clinical observation was after 14 and 30 days from implantation. The animals were clinically evaluated every day in order to assess wound healing and reaction to the implant inserted. Some animals were randomly selected and sacrificed after the end of clinical observation (two groups of four animals after 14 and 30 days). Eyeballs were removed postmortem and histopathologically evaluated. Other animals have been left for further observation.

\subsection{Non-perforating deep sclerectomy \\ with and without inserted implant: preparation of animals for surgery}

The animal experiments were performed according to the EU ISO 10993-6 guidelines and the study protocol was approved by the local bioethical committee (Krakow, Poland). The same experienced surgeon performed all operations with the same surgical procedure. The study was performed using eight New Zealand white rabbits, age 9-12 months weighting between 3.0 and $4.0 \mathrm{~kg} .12-18 \mathrm{~h}$ before surgery the feeding was stopped, with ensured free access to water. The intravenal access was guaranteed by insertion cannule 20GA (Venflon BD 1.0) to the left or right marginal ear vein. Before general anasthesia all animals were subjected to intramuscular injection of $0.06 \mathrm{mg} / \mathrm{kg}$ atropine (Atropinum Sulfuricum $0.5 \mathrm{mg}$, 
Polfa), $10 \mathrm{mg} / \mathrm{kg}$ xylazine and $3 \mathrm{mg} / \mathrm{kg}$ azaperon (Stresnil, Janssen Animal Health BVBA). Animals were anaesthetized with ketamin $5.0-15.0 \mathrm{mg} / \mathrm{kg}$ i.v. (bolus dose) with subsequent adding maintaining dose of $1 / 5-1 / 4$ of the initial dose, depending on anaesthetic effect. Immediately before surgery two drops of $0.5 \%$ poxymetacain hydrochlorate were given to conjunctival sac (Alcaine, s.a. Alcon-Couvreue n.v.).

\subsection{Non-perforating deep sclerectomy with inserted implant (study group)}

An intracorneal bridle suture was first placed on the limbal cornea (8-0). After pulling down the eyeball, the conjunctiva was opened. In the area of the ciliary body, $5 \mathrm{~mm}$ incision of sclera was performed, $10 \mathrm{~mm}$ from the limbus. The superficial square scleral flap measuring $5 \times 5 \mathrm{~mm}$ was dissected $1 \mathrm{~mm}$ into clear cornea. The aim of very deep dissection of corneal flap was partial exposure of ciliary body (modification with reference to traditional NPDS surgery). The membrane implant of equilateral triangle shape (side length: $3 \mathrm{~mm}$ ) was inserted into the exposed part of ciliary body. The superficial scleral flap was closed with two single straight sutures (9-0). The dissected conjunctiva was closed with a running suture. In the control group the identical operation was performed without the implant insertion. Postoperatively, analgesic drugs (tramadol 1-2 mg/kg) and systemic antibiotics: amicacin and cefuroxim (10 and $25-50 \mathrm{mg} / \mathrm{kg}$, respectively) were administered in the course of wound healing, minimum for 7 days. Topical Tobradex (Alcaine, s.a. Alcon-Couvreue n.v.) two guts to each conjunctival sac was administered twice daily for 14 days.

\subsection{Clinical observation}

Clinical observation lasted 30 days. The primary endpoints were the course of wound healing and disapperance of postoperational lesions. In clinical evaluations the following endpoints were taken into consideration: pupil reaction to the light, light intolerance, leakage from conjunctival sac, swelling and inflammation of concjunctiva, sclera swelling and redness in wound area, postoperative scleral adhesions, time of wound healing and clinical status of the eyeball after 1 month observation. For evaluation of clinical lesions and wound healing the modified 4-graded scoring system (0-3) was adopted according to Hoekzem [18] and Erkiliç [19] (Table 1).

\subsection{Histopathological evaluation}

Enucleated eyeballs were subjected to histopathological procedures. As the fixative $10 \%$ buffered commercially available formaline ( $4 \%$ formaldehyde) was used. To prepare the samples for histopathological evaluation, the eyeball was dissected along the long axis, next to the inserted implant, and in the case of control group-next to the incision and suprasclerally visible sutures, through the optic disc. The lens was subsequently removed and the material was prepared for further laboratory procedures. It was placed into the dehydrated containers by using increasing methanol concentrations. Next the tissue was placed into xylen to harden and clean the tissue. Finally, the sample was immersed three times into liquid paraffin. This stage of material preparing was realized automatically for about $17 \mathrm{~h}$. The prepared material was immersed again with liquid paraffin at $60^{\circ} \mathrm{C}$, followed by placing it on the specially designed frame to obtain paraffin block containing the sample. The embedded material was cut with microtone. The thickness of the tissue sections was 3-4 $\mu \mathrm{m}$. After drying of the dissected material on slides, it was stained with hematoxylin (blue colour of nucleus) and eosin (pink colour of cytoplasm and extracellular elements). The quantitative results were presented as mean \pm SEM. Statistical comparisons of clinical symptoms and histopathological evaluation between the groups (study and control) and within the groups were made with Student's $t$ test, and a chosen level of significance of $P \leq 0.05$ was considered significant.

Statement of Ethics We certify that all applicable institutional and governmental regulations concerning the ethical use of animals were followed during this research.

\section{Results}

The course of wound healing and intensity of clinical symptoms are presented in Fig. 1. Apathy of mild degree and pain symptoms were observed in rabbits for 0-5 days (average 2 days), loss of appetite was observed for 0-3 days (average 1 day). Immediately after surgery in eight animals accommodation disturbancy as mydriasis and the lack of reaction to the light were observed, lasting in most animals 1-7 days (average 2.4) (Fig. 1a, b). In one rabbit, the symptoms were present for 22 days, whereas in six rabbits moderate to severe light intolerance during 1-4 days (average 1.6) was observed (Fig. 1a, b). In both eyeballs of six other rabbits a moderate to severe seropurulent excharge from conjunctival sac lasting 1-4 days (average 2.5) was observed (Fig. 1a) Immediately after surgery in all evaluated eyeballs mild to severe swelling and conjunctiva inflammation, redness and congestion of sclera in the area of wound were observed (Fig. 1a, b, d). Conjunctivitis lasted 1-13 days, and its duration was statistically significant shorter in the study group $(P \leq 0.05)$ (Fig. 1 a, b, d). After 14 days, the symptoms of 
Table 1 Modified scale of clinical lesions according to Hoekzem [17] and Erkiliç [18]

\begin{tabular}{|c|c|c|c|}
\hline \multirow[t]{2}{*}{ Clinical signs } & \multirow[t]{2}{*}{ Duration time } & \multicolumn{2}{|l|}{ Grade } \\
\hline & & Grade & Score \\
\hline $\begin{array}{l}\text { Mydriasis, without } \\
\text { reaction to light }\end{array}$ & Days & Not evaluated & Not evaluated \\
\hline \multirow[t]{4}{*}{ Photophobia } & \multirow[t]{4}{*}{ Days } & No & 0 \\
\hline & & Mild & 1 \\
\hline & & Moderate & 2 \\
\hline & & Severe & 3 \\
\hline \multirow[t]{4}{*}{ Leakage from conjunctival sac } & \multirow[t]{4}{*}{ Days } & No & 0 \\
\hline & & Mild & 1 \\
\hline & & Moderate & 2 \\
\hline & & Severe & 3 \\
\hline \multirow{4}{*}{$\begin{array}{l}\text { Swelling and inflammation } \\
\text { of concjunctiva }\end{array}$} & \multirow[t]{4}{*}{ Days } & No & 0 \\
\hline & & Mild & 1 \\
\hline & & Moderate & 2 \\
\hline & & Severe & 3 \\
\hline \multirow{4}{*}{$\begin{array}{l}\text { Sclera swelling and } \\
\text { redness in wound area }\end{array}$} & \multirow[t]{4}{*}{ Days } & No & 0 \\
\hline & & Mild & 1 \\
\hline & & Moderate & 2 \\
\hline & & Severe & 3 \\
\hline \multirow{4}{*}{$\begin{array}{l}\text { Scleral hyperemia in } \\
\text { wound area }\end{array}$} & \multirow[t]{4}{*}{ From the day after operation } & No & 0 \\
\hline & & Mild & 1 \\
\hline & & Moderate & 2 \\
\hline & & Severe & 3 \\
\hline \multirow[t]{4}{*}{ Adhesion } & \multirow[t]{4}{*}{ From the day after operation } & No & 0 \\
\hline & & Mild & 1 \\
\hline & & Moderate & 2 \\
\hline & & Severe & 3 \\
\hline \multirow[t]{4}{*}{ Scar } & \multirow[t]{4}{*}{ From the day after operation } & No & 0 \\
\hline & & Mild & 1 \\
\hline & & Moderate & 2 \\
\hline & & Severe & 3 \\
\hline Minimum & & & 0 \\
\hline Maximum & & & 21 \\
\hline
\end{tabular}

inflammation and swelling of conjunctiva were no longer present in any animal (Fig. 1d). Swelling and redness of sclera in the area of wound lasted on average 3-20 days $(9.5 \pm 3.6$ and $9.0 \pm 4.2$ in the study group and control group, respectively) (Fig. 1a, b). In both groups swelling and redness in the area of scleral wound significantly decreased. However, in 13 eyeballs from the study group and 14 from control group a mild to moderate swelling and redness were still present (Fig. 1b). Difference between the groups was not statistically significant. After 1 month observation in six eyeballs in study group and seven in control group a mild to moderate redness was still present, without features of swelling. In all eyeballs of the study group scleral congestion in the area of the wound was observed, while in 15 eyeballs of the control group it was still present 14 days after surgery. At the same time in both groups a statistically significant decrease in congestion from severe to moderate and mild was observed. Difference between both groups was not statistically significant. After 1 month, in 16/18 eyeballs in the study group and in $14 / 18$ eyeballs in the control group a mild to moderate congestion was still present. No difference in the degree of congestion between the groups was observed. In both groups mild to severe adhesions in wound area were present on average 4.5 (3-7) days after surgery (Fig. 1a, b). In both groups adhesions were found in 20 evaluated eyeballs. After 14 days, adhesions were still present in 18 and 16 eyeballs in the study group and the control group, respectively (Fig. 1c). Their intensity did not significantly change, while difference between the group was 


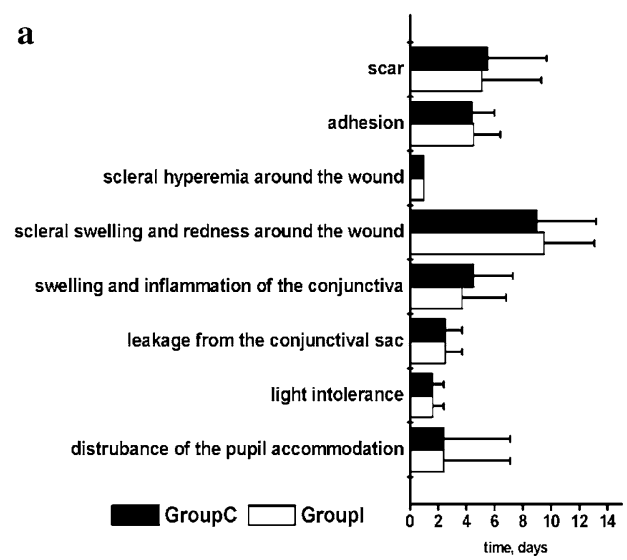

c

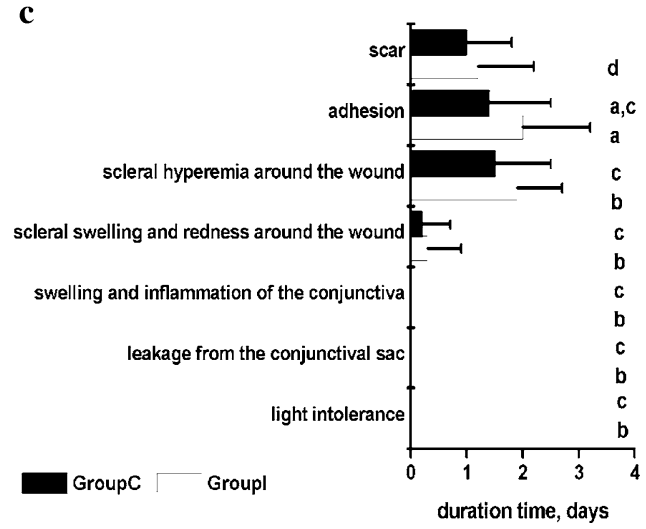

Fig. 1 Clinical observations: a Duration of clinical symptoms during 30-day observation; group $C$ control group (eyeballs without implant), group $I$ study group (eyeballs with inserted implant); b Maximum of intensity of clinical symptoms and the course of wound healing after 30-day observation; $a$ statistical difference SD between groups $P \leq 0.05, b$ SD between days 1 and 14 in study group $P \leq 0.05, c$ SD between days 1 and 14 in control $P \leq 0.05$; c Intensity of clinical symptoms and the course of wound healing after

statistically significant. One month after surgery adhesions in both groups were still present in 12/18 of the evaluated eyeballs in each group, without statistically significant difference between groups, Fig. 1d. Between 14 and 30 days the size and extent of adhesions did not decrease significantly. In both groups wound cicatrisation process was observed on average from the day 5 (5-11). The observed cicatrization process was from a mild to moderate degree, and only in two eyeballs within the study group the stage three of cicatrization was present. After 14 days from surgery in 12 eyeballs in the study group and in eight eyeballs in control group small scars were noticed (Fig. 1c). There was no significant decrease of scar size. Differences between groups were not statistically significant. One month after surgery small scars were still present in six eyeballs in study group and four in control group. In both groups a significant decrease of scar size was observed between days 14 and 30 after surgery. There was
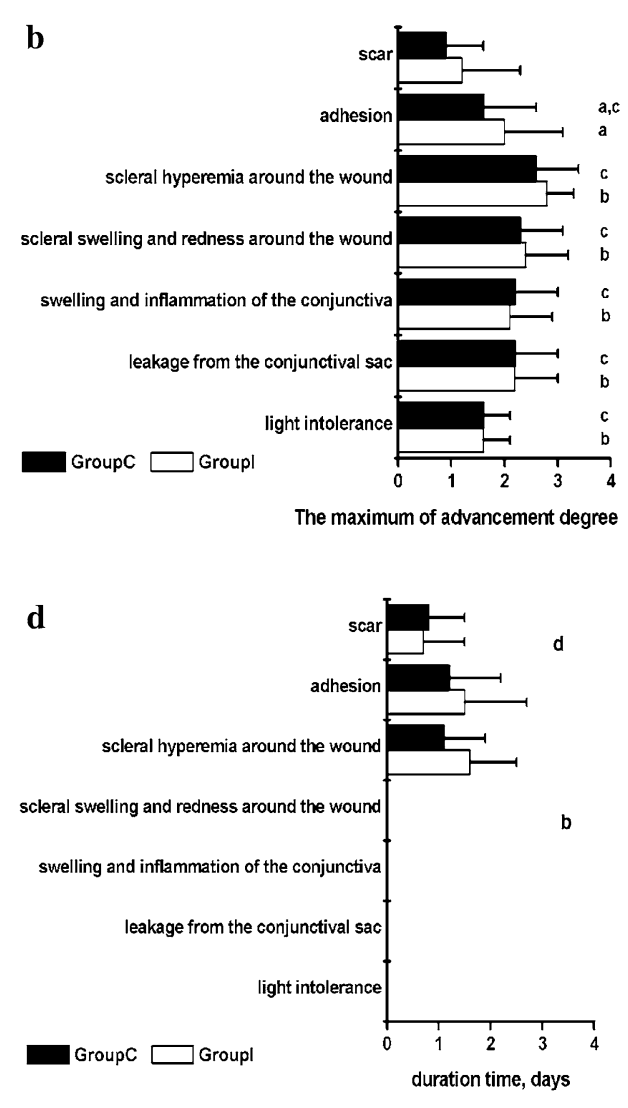

14 days of observation; $a$ SD between groups I/C $P \leq 0.05, b$ SD between days 1 and 14 in study group $P \leq 0.05, c$ SD between days 1 and 14 in control group $P \leq 0.05, d$ SD between days 14 and 30 in study group $P \leq 0.05$; d Intensity of clinical symptoms and the course of wound healing after 30 days of observation; $a$ SD between groups $P \leq 0.05, b$ SD between days 1 and 14 in study group $P \leq 0.05, c$ SD between days 1 and 14 in control $P \leq 0.05, d$ SD between days 14 and 30 in study group $P \leq 0.05$

no a significant difference between the groups (Fig. 1d). One month after surgery postoperative side effects, like congestion and/or scar and/or adhesion were still present in 11 eyeballs in the study group and 10 eyeballs in the control group. From the whole group consisting of 18 animals, on the last day (30 day) lesions were more evident in the eyeballs with the implants in seven animals and in five animals without implants. In six animals lesions after surgery in both eyeballs were comparable or they were not noticed at all.

Results of histopathological evaluation of removed eyeballs are gathered in Table 2 and Fig. 2. On histopathological evaluation, an increase of amount of resorption granulation was the only reaction observed around the implant, defined as not matured connective tissue, which is always present in case of tissue destruction. Multinucleated histocytes, phagocyting, removing altered tissue and foreign bodies are typical features of this tissue. After 
Table 2 The histopathological evaluation

\begin{tabular}{|c|c|c|c|c|c|c|c|c|}
\hline \multirow[t]{3}{*}{ Changes in histopathological evaluation } & \multicolumn{4}{|l|}{ Day 14} & \multicolumn{4}{|l|}{ Day 30} \\
\hline & \multicolumn{2}{|l|}{$\mathrm{I}(n=4)$} & \multicolumn{2}{|c|}{$\mathrm{C}(n=4)$} & \multicolumn{2}{|l|}{$\mathrm{I}(n=4)$} & \multicolumn{2}{|c|}{$\mathrm{C}(n=4)$} \\
\hline & Average & Range & Average & Range & Average & Range & Average & Range \\
\hline \multicolumn{9}{|l|}{ Implant } \\
\hline Resorption granulation tissue around implant & $0.50^{\mathrm{a}}$ & $0.00-2.00$ & - & - & $2.25^{\mathrm{a}}$ & $0.00-3.00$ & - & - \\
\hline Chronic inflammatory infiltration around implant & 0.00 & 0.00 & - & - & 0.75 & $0.00-3.00$ & - & - \\
\hline \multicolumn{9}{|l|}{ Sclera } \\
\hline Resorption granulation tissue in sclera & 0.75 & $0.00-3.00$ & 0.75 & $0.00-3.00$ & 0.00 & 0.00 & 0.00 & $0.00-2.00$ \\
\hline Scleral dissection & 0.00 & 0.00 & 0.75 & $0.00-3.00$ & 0.00 & 0.00 & 0.00 & 0.00 \\
\hline Inflammatory infiltration & 0.00 & 0.00 & 0.25 & $0.00-1.00$ & 0.00 & 0.00 & 0.00 & 0.00 \\
\hline \multicolumn{9}{|l|}{ Sutures } \\
\hline Resorption granulation tissue & 1.00 & $0.00-2.00$ & 0.75 & $0.0-3.00$ & 0.75 & $0.00-3.00$ & 0.00 & 0.00 \\
\hline \multicolumn{9}{|l|}{ Ciliary body } \\
\hline Resorption granulation tissue & 0.75 & $0.00-3.00$ & 0.00 & 0.00 & 0.25 & $0.00-1.00$ & 0.00 & 0.00 \\
\hline Chronic inflammation & 0.50 & $0.00-2.00$ & 0.00 & 0.00 & 0.50 & $0.00-2.00$ & 0.00 & 0.00 \\
\hline Stromal oedema & 0.00 & 0.00 & $0.00^{\mathrm{a}}$ & 0.00 & 0.50 & $0.00-2.00$ & $1.25^{\mathrm{a}}$ & $0.00-2.00$ \\
\hline \multicolumn{9}{|l|}{ Subconjunctival lesions } \\
\hline Granulation tissue & 0.75 & $0.00-2.00$ & 0.00 & 0.00 & 0.00 & 0.00 & 0.00 & 0.00 \\
\hline Haemorrhages & 0.25 & $0.00-1.00$ & 0.00 & 0.00 & 0.00 & 0.00 & 0.00 & 0.00 \\
\hline Fibrosis & 0.50 & $0.00-2.00$ & 0.00 & 0.00 & 0.50 & $0.00-2.00$ & 0.00 & 0.00 \\
\hline Hyalinization & 0.50 & $0.00-2.00$ & 0.00 & 0.00 & 0.50 & $0.00-2.00$ & 0.00 & 0.00 \\
\hline \multicolumn{9}{|l|}{ Whole eyeball } \\
\hline Haemorrhages & 0.50 & $0.00-2.00$ & 0.75 & $0.00-3.00$ & 0.25 & $0.00-1.00$ & 0.00 & 0.00 \\
\hline Capillary proliferation & 0.00 & 0.00 & 0.00 & 0.00 & 0.75 & $0.00-3.00$ & 0.50 & $0.00-2.00$ \\
\hline Congestion & 0.00 & 0.00 & 0.00 & 0.00 & 0.50 & $0.00-1.00$ & 0.00 & 0.00 \\
\hline Purulent infiltration & 0.00 & 0.00 & 0.75 & $0.00-3.00$ & 0.00 & 0.00 & 0.50 & $0.00-2.00$ \\
\hline
\end{tabular}

${ }^{a}$ Significant difference at $P \leq 0.05$ The evaluation scale of histological signs in the range from 0 to 3 points. 0 no signs, 1 mild, 2 moderate, 3 severe, $I$ implant, $C$ control

14 days, a moderate amount of granulation was observed in one eyeball, and after 30 days a high amount of granulation was present in three eyeballs. The observed difference inside the sclera related to both times of observation was statistically significant, at $P \leq 0.05$ (Table 2). In spite of scleral dissection with chronic inflammatory, inflammation could also be seen. In eyeballs with the inserted implants only granulation was present. After follow up of 14 days in one eyeball a high amount of granulation tissue was found. In one eyeball of the control group after 14 days a high amount of granulation tissue was present, and after 30 days a moderate amount of granulation in two eyeballs was noticed. In the ciliary body there was a high amount of granulation in one eyeball with the implant and a small amount of granulation in the other one after 14 and 30 days, respectively. Moreover, in one eyeball a moderate inflammation on days 14 and 30 was observed. In control only a mild to moderate stromal oedema was observed in the ciliary body, without any features of histopathological lesions. The difference between both groups was statistically significant (Table 2). In the group with the implants, 14 days after surgery a small amount of granular tissue was observed subconjunctivally in two eyeballs; in some eyeballs a mild inflammation with focal sclerosis and hyalinization was observed in this area. In control group focal fibrosis and hyalinization of a moderate degree was observed subconjunctivally in one eyeball. After 1 month, no subconjunctival changes were found on histopathological evaluation in any of the analyzed groups. Additionally, in few eyeballs moderate or severe haemorrhages were noticed on day 14 in study and control group. A mild and moderate fibrosis was found in two eyeballs in control group. After 1 month, an abundant connective tissue and moderate number of thin-walled vessels created in both groups; additionally, in one eyeball of the study group small single haemorrhages and congestion were observed. On days 14 and 30, in one eyeball in control group a purulent inflammatory infiltration, consisting mainly of granulocytes, was found. No purulent infiltration was observed in group with the implant. 
Fig. 2 Histopathological evaluation of removed eyeballs: a 14th day without implantcongestion of sclera, with focal areas of resorption granular tissue, formed in nodules, localized around surgical suture; b 14th day with implant: the implant in central part surrounded by an abundant granular tissue; c 1 month without implant-abundant granular tissue; d 1 month with implant - the implant visible in the central part surrounded by unspecific partially resorption granular tissue, resorption granular tissue can be seen also sub conjunctivally, oedema of cillary body
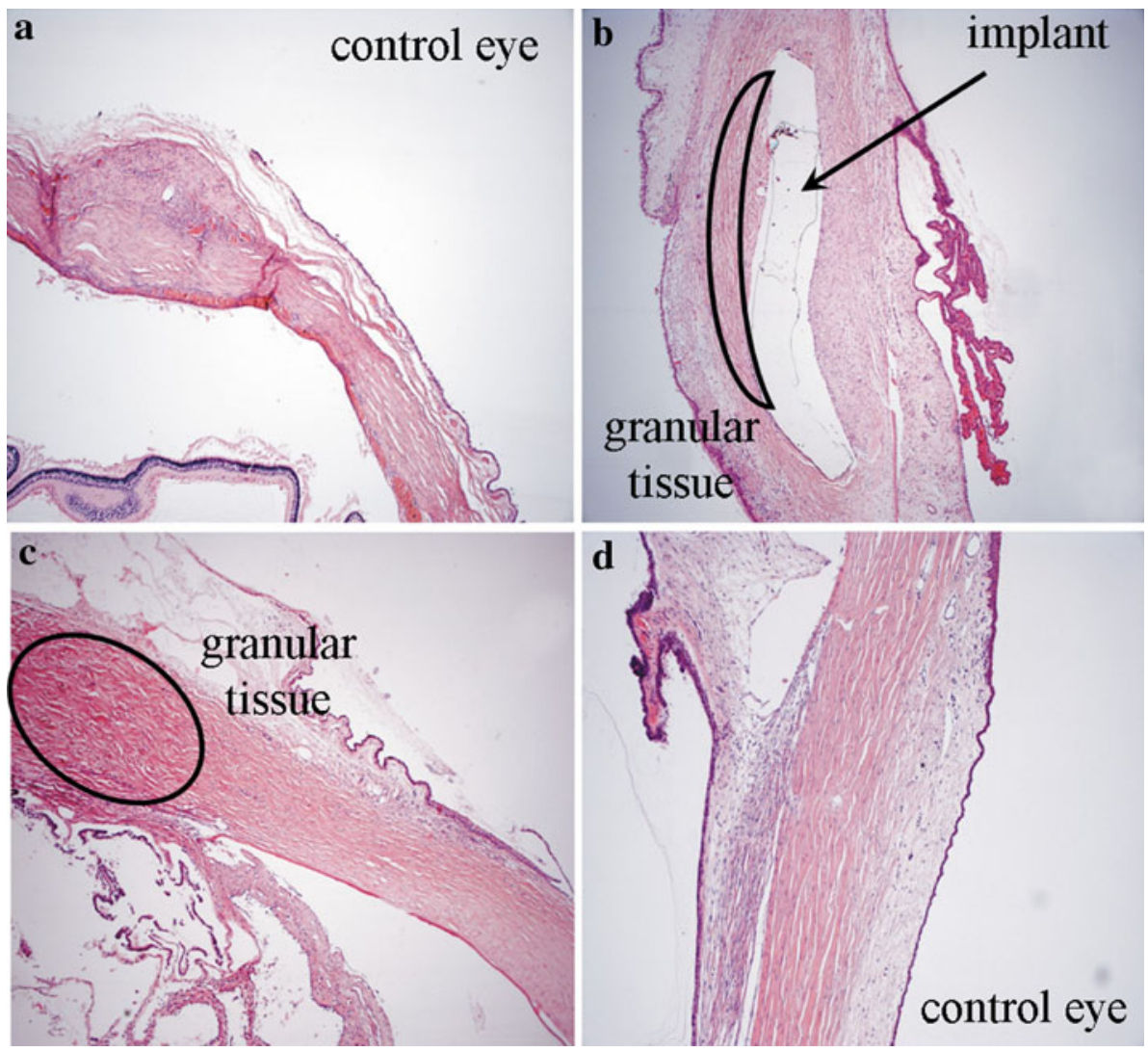

\section{Discussion}

The purpose of this study was to assess on animal model a new biomaterial for glaucoma treatment. This biomaterial was used for manufacturing implants applied in glaucoma treatment by a non-perforating deep sclerectomy method. The biomaterial was manufactured in the form of a polymeric membrane containing a system of canalicular open pores (open porosity about 50\%) enabling free intraocular fluid circulation. The membrane allows to keep the intraocular pressure on a physiological level. In our previous studies, the optimal porous interconnected canalicular microstructure aimed at leveling the pressure gradient was determined [23]. The elaborated material has a suitable biomechanical durability and is resistant to long-lasting static and dynamic loading. Additional advantage of the material are its physicochemical surface properties, meeting the requirements for ophtalmological implants, namely hydrophobicity and low surface energy that hinder blocking of membrane pores [24].

In the previous study the in vitro biocompatibility of this material was proved on mouse fibroblast cell line 3T3/Balb using a direct contact method [24]. Degradation studies performed according to the EN-PN ISO 10993-12 standard confirmed stability and inertness of composite membrane in vitro conditions.
The first part of the study performed on rabbit model was realized to verify and confirm the results of in vitro study and to determine the animal eyeball reaction to the inserted implants. Observations in the course of wound healing and histopathological changes in relatively short time (1 month) were made. In this time some clinical symptoms indicating that the course and the reactions intensity seem to be typical for wound healing process. On the first day after surgery moderate to severe conjunctivitis with oedema and discharge from the conjunctival sac are the main observed clinical symptom. The main factor responsible for severe inflammation of the conjunctival sac mucous membrane is its mechanical irritation during surgery. Statistically significant difference $(P \leq 0.05)$ in duration time of conjunctivitis was observed between the study and control groups favoring the study group. In some rabbits immediately after surgery mydriasis with photophobia was observed. It seems, however, that these symptoms were not eyeball reaction to inserted implant, since the duration and intensity of symptoms in both groups were identical $(P=1.00)$. In evaluation of wound healing and tissue reaction to implant the symptoms relating to the site of implant insertion are extremely important. They include redness, oedema and congestion of sclera in wound area as well as adhesions and scar developed during healing. Immediately after surgery a severe 
scleral congestion in wound area with a moderate to severe redness and oedema of similar intensity were observed in both groups. On consecutive healing days adhesion and scar were present. Difference between groups was observed for adhesion only, and intensity of other symptoms was similar in both groups. In both groups (study and control), the course of wound healing was very similar accompanied by resolution of redness and scleral oedema. After 1 month observation of scleral wound area, congestion adhesion and scar formation had similar intensity in both groups. During the first month the course of wound healing was similar in both groups. In the eyeballs group with the implants neither symptoms of intolerance nor implant rejection were observed. Histopathological study revealed, however that there were many changes observed in different anatomical parts of eyeball. In the proximity of the implant site resorption of granular tissue and a mild inflammation were observed. It is typical for healing process with the feature of foreign body reaction. It is important that a similar granular reaction was found in the area of sutures in both groups. Numerous histopathological lesions in area of sclera, ciliary body, conjunctiva or entire eyeball were very mild with no statistically significant difference between the groups. No lesions typical for implant intoleration were found on histopahological evaluation. It is worth noticing, however that no purulent inflammation was observed in the study group, contrary to that of purulent inflammation observed in control. Similar studies performed with the use of different type of implants showed analogous course of healing and similar histopathological changes. The crucial period in wound healing after implant insertion were the first 2 weeks after surgery. It was confirmed in similar studies of implants made of silicone material [18, 20], catgut, nylon [18], zirconium [21], natrium hyaluronate [20], collagen [22, 23] and its derivates Bio-1, Bio-2, Bio-3 [6], as well as synthetic polymers and copolymers e.g. HEMA, HEMA-co-MMA [4], e-PTFE [7] or SIBS [9]. The most pronounced clinical symptoms were observed on the first 4-5 days after surgery. Mild clinical symptoms were observed 14 days after surgery, and some of them were still present after 30 days. Only in studies evaluating implants made of catgut and its polymers mild clinical symptoms were observed 1 month after surgery $[22,23]$. They include proliferation of capillaries in sclera, inflammatory infiltration around implant $[18,20-22,24,25]$, proliferation of connective tissue around implant [20, 26], granular reaction [18, 20, 24], fibrosis [18, 20], inflammation around sutures [18, 23]. As it results from available literature the lesion sites increase within the period of 14-30 days after surgery, what may be associated with a natural healing process and tissue reconstruction after surgery.

\section{Conclusions}

While the in vivo study of the terpolymer-based biomaterial will be continued, the following conclusions can be reached at present:

Clinical symptoms of a moderate degree were observed, and histopathological changes were typical for a foreign body implantation. At the end of the in vivo study (after 30 day implantation) no significant difference was noted between the study and control groups. Moreover, similarities observed in both groups and relatively mild histopathological changes in tissue surrounding the inserted implants indicate that symptoms observed in the in vivo rabbit model may come from deep scleral trauma caused by surgery, and not by the presence of the implant itself.

Data obtained from previous in vitro study, in conjunction with the in vivo evaluation of the terpolymerbased implant are pertinent to the planned biomedical use $[15,17]$. There is reasonable requirement of continuation of preclinical studies and evaluation of implant during longer period of observation. It must however be reserved that the reaction and toleration of biomaterial used in this study may differ in human and other mammal species.

Positive evaluation of terpolymer-based implant material may provide a rationale to use it into clinical studies in eyeball surgery.

Acknowledgements The study was supported by Ministry of Science and Higher Education, Grant No N 518028 32/1769. Ewa Stodolak is beneficiary of The Foundation for Polish Science (FNP) in Domestic Grants for Young Scientists Program.

Open Access This article is distributed under the terms of the Creative Commons Attribution Noncommercial License which permits any noncommercial use, distribution, and reproduction in any medium, provided the original author(s) and source are credited.

\section{References}

1. Eldaly M, Anand N, Bunce C,Khafagy M. Non-penetrating filtration surgery versus trabeculectomy for open angle glaucoma. (Protocol) Cochrane Database Syst Rev. 2008; Issue 2. CD007059. DOI:10.1002/14651858.CD007059.

2. Burr JM, Mowatt G, Hernández R, Siddiqui MAR, Cook J, Lourenco $\mathrm{T}$, et al. The clinical effectiveness and cost-effectiveness of screening for open angle glaucoma: a systematic review and economic evaluation. Health Technol Assess. 2007;11(41): $1-206$.

3. Khaw PT, Shah P, Elkington AR. Glaucoma-2: treatment. BMJ. 2004;328(7432):156-8.

4. King A, Migdal C. Clinical management of glaucoma. J R Soc Med. 2000;93(4):175-7.

5. Dada T, Aggarwal A, Minudath KB, Vanathi M, Choudhary S, Gupta V, Sihota R, Panda A. Post-penetrating keratoplasty glaucoma. Indian J Ophthalmol. 2008;56(4):269-77. 
6. Mandal AK. Current concepts in the diagnosis and management of developmental glaucomas. Indian J Ophthalmol. 1993;41: 51-70.

7. Schwartz KS, Lee RK, Gedde SJ. Glaucoma drainage implants: a critical comparison of types. Curr Opin Ophthalmol. 2006;17(2): 181-9.

8. Ishida K, Mandal AK, Netland PA. Glaucoma drainage implants in pediatric patients. Ophthalmol Clin North Am. 2005;18(3): 431-42.

9. Chiou AGY, Mermoud A, Underdahl JP, Schnydrer CC. An ultrasound biomicroscopic study of eyeballs after deep sclerectomy with collagen implant. Ophthalmology. 1998;105:746-50.

10. Klinge U, Klosterhalfen B, Ottinger AP, Junge K. PVDF as a new polymer for the construction of surgical meshes. Biomaterials. 2002;23:3487-93.

11. Chunseng F, Baoli S, Guomin L, Yonglie W. Preparation and properties of microporous membrane from poly(vinylidene fluoride-co- tetrafluoethylene) for membrane distillation. J Memb Sci. 2004;237:15-24.

12. Shaarawy T, Nguyen Cr, Achache F. Comparative study between deep scleretomy with and without collagen implant: long term follow-up. Br J Ophthalmol. 2004;88(1):95-8.

13. Stodolak E, Czajkowska B, Blazewicz M, Mikolajczyk T, Wolowska-Czapnik D. In vitro behavior of PP-PVDF-PTFE terpolymer modified with alginate fibres. Eng Biomater. 2004; 38-42:208-11.

14. Zaczynska E, Czarny A, Zywicka B, Stodolak E, Blazewicz M. The study of cytotoxity of fibrous composite materials. Eng Biomater. 2006;54-55:15-8.

15. Stodolak E, Wieczorek J, Gumula T, Blazewicz S, Leszczynski $\mathrm{R}$. The new generation of composite membranes for ophthalmology application. In: 17th International conference on composite materials. July 27-31, 2009, Edinburgh, UK.

16. Stodolak E, Krok M, Gumula T, Blazewicz S. Composite membranes materials for ophthalmological implants. Composites. 2009;4:352-7.

17. Stodolak E, Zaczynska E, Blazewicz M, Wolowska-Czapnik D, Leszczynski R. Membrane composite materials for medical application. Primary material and biological study. Composites. 2006;4:47-51.

18. Hoekzema R, Murray PI, van Haren MA, Helle M, Kijlstra A. Analysis of interleukin-6 in endotoxin-induced uveitis. Invest Ophthalmol Vis Sci. 1991;32:88-95.

19. Erkiliç K, Ozkiriş A, Evereklioglu C, Kontaş O, Güler K, Dogan H. Deep sclerectomy with various implants: an experimental and histopathologic study in a rabbit model. Ophthalmologica. 2004;218:264-9.

20. Kaluzny JJ, Jozwicki W, Wisniewska H. Histological biocompatibility of new, non-absorbable glaucoma deep sclerectomy implant. J Biomed Mater Res B. 2007;81(2):403-9.

21. Basso A, Roy S, Mermoud A. Biocompatibility of an X-shaped zirconium implant in deep sclerectomy in rabbits. Graefes Arch Clin Exp Ophthalmol. 2008;246(6):849-55.

22. Rönkkö S, Rekonen P, Sihvola R, Kaarniranta K, Puustjärvi T, Teräsvirta $\mathrm{M}$, Uusitalo $\mathrm{H}$. Histopathology of the three implanted degradable biopolymers in rabbit eyeball. J Biomed Mater Res A. 2009;88(3):717-24.

23. Nguyen C, Boldea RC, Roy S, Shaarawy T, Uffer S, Mermoud A. Outflow mechanisms after deep sclerectomy with two different designs of collagen implant in an animal model. Graefes Arch Clin Exp Ophthalmol. 2006;244(12):1659-67.

24. Jallet V, Gautier SE, Parel JM, Matsui T, Haefliger I, Kondo H, Kato H, Savoldelli M, Pouliquen Y. Novel synthetic meshwork for glaucoma treatment. I. Design and preliminary in vitro and in vivo evaluation of various expanded poly(tetrafluoroethylene) materials. J Biomed Mater Res. 1999;47(2):260-9.

25. Acosta AC, Espana EM, Yamamoto H, Davis S, Pinchuk L, Weber BA, Orozco M, Dubovy S, Fantes F, Parel JM. A newly designed glaucoma drainage implant made of poly(styrene-bisobutylene-b-styrene): biocompatibility and function in normal rabbit eyeballs. Arch Ophthalmol. 2006;124(12):1742-9.

26. Kivalo M, Siren V, Raitta C, Immonen I. Biodegradable tube implants in experimental glaucoma surgery in the rabbit. J Mater Sci Mater Med. 1999;10(1):53-8. 